\title{
Prediction of 3-dimensional heat treatment model during the friction stir spot welding of
}

\author{
AA 6061 \\ DOI : 10.36909/jer.12317 \\ Ritesh Jaiswal*, Rajnish Singh*, Dr. Saadat Ali Rizvi** $^{*}$ \\ *Mechanical Engineering department, Kamla Nehru Institute of Technology, Sultanpur -228118 \\ -India \\ **Faculty member, University Polytechnic, Jamia Millia Islamia, New Delhi \\ 110025 \\ **Corresponding Author: sarizvi1@jmi.ac.in/saritbhu@gmail.com,
}

\begin{abstract}
In this research work, a die steel tool was used to join the two aluminium sheets together on a radial drill machine. For this, a cylindrical-shaped tool was fabricated. This tool is then clamped into the drill machine tool post. This rotating tool is then inserted/indented into the workpiece thus generating heat due to friction. The of the deformation of aluminium starts near the vicinity of the die steel tool impression. The tool transferred the soft material from the tip to the plunger. The plunger is in contact with the Aluminum sheet. Soften material is forged on the sheet with the help of a plunger and thus creating a solid phase joint between the Aluminum sheets. Threedimensional numerical modelings were performed on Ansys software. A 3-D heat transfer model was used to solve the problem of friction stir spot welding (FSSW). This model was solved by applying the energy conservation equation. This model involves the heat generated at the boundary of the workpiece (AA) and the rotating tool and for study, the problem, steady-state heat transfer equation was used. The numerically computed and the measured values are compared to validate the results.
\end{abstract}


Keywords: friction stir spot welding (FSSW), aluminium alloys (AA), modeling, heat transfer.

\section{Introduction}

Before the 1990s, we had various welding technologies such as gas welding, arc welding, etc. to weld one substance to another which may be similar or dissimilar to having different mechanical, chemical, and physical properties. But in these welding processes, many disadvantages have been found such as hot cracking, porosity, and residual stresses Yang X et al. (2015). The main problem was found in the formation of an oxide film on the surface of Aluminum during arc welding. This leads to the hardening of the Aluminum surface. This hardened surface is very difficult to machine. So in 1991, Thomas W.M at The Welding Institute (TWI) of UK discovered friction stir welding. Friction stir welding (FSW) is a solid (Singh R., Yadav A. 2018) state joining processes in which two similar or dissimilar materials are bonded with each other by mechanical bonding. In FSW joint formation take place due to the plastic deformation of materials and in the FSW process sufficient heat is produced bythe rubbing process to plasticized the workpiece. As the material gets plasticized a compressive force is applied and both the parts are joined to each other (Jedrasiak P et al.2018). This joined workpiece is free fromany defects such as porosity, hot cracking, etc. Few studies have been examined in understandingthe process of friction stir welding and modeling friction welding. AA 6061 aluminium alloy is frequently used for lightweight structures due to its excellent mechanical quality and corrosion resistance quality (Leon J S., Jayakumar V. 2015). Singh R et al. studied the effect of different FSW process parameters and rotating tools on the mechanical quality of AA 6063 and they concluded that frictional heat is directly proportional to the rotational speed of the tool. Many researchers have developed a thermo-mechanically coupled model of friction stir spot welding via finite element method (FEM) (Gao Z et al.2013, Miyazaki Y et al.2013 and Zhu R et al.2020), 
meshless particle method (Armansyah et al.2020). Nguyen H P et al. (2021) studied the temperature distribution of aluminium during the FSSW process and they mentioned in their result that the temperature of the weld zone increases on increasing the tool rotational speed. Ghetiya N.D et al.(2015) developed a thermal model by FEM to predict the peak temperature during the FSW of AA 8011 and they concluded that both model and experimental values are in good agreement with each other. Peng C et al. (2021) analyzed the thermal behavior and mechanical properties during the underwater FSW process of AA 2219 and they concluded that for underwater FSW surface heat flux of tool shoulder is greater than that for normal FSW. Ulysse P (2002) presented a 3-D model for temperature measurement and the author declared that the agreement between predicted and measured temperatures has been found reasonable. Bilgin M B et al. (2017) developed 3-D FEM model of friction drilling process during hot forming process and they concluded that there is a good accuracy was observed between experimental and FEA result.

\section{Experimental setup}

Friction stir spot welding (FSSW) was performed on the drilling machine to weld the AA 6061 alloy in butt configuration. The drilling machine can be rotated in the lateral and longitudinal direction both. Figure 1 shows the experimental setup for the FSSW process. A radial drill machine was converted into friction stir spot welding. The drill machine was not yet utilized for spot welding purpose 


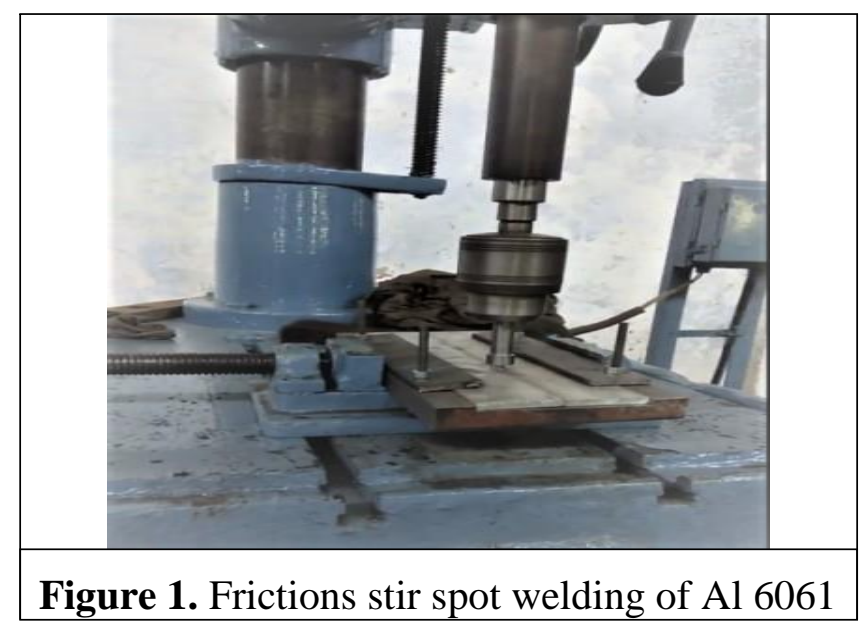

The drill machine used in this process was 3 phase AC power source with a gearbox attached to Change the spindle speed and the spindle speed of the drill machine was $1250 \mathrm{rpm}, 1300 \mathrm{rpm}$, $1400 \mathrm{rpm}$, and $1500 \mathrm{rpm}$ respectively. AA 6061 of $300 \mathrm{~mm} \mathrm{X} 50 \mathrm{~mm} \mathrm{X} 3 \mathrm{~mm}$ was used as a base metal.AA 6061 was welded by die steel tool as the strength of die steel tool is very excellent and it can penetrate the aluminium alloys easily and performed joining easily. The chemical composition of AA 6061 as a base metal is tabulated in Table 1

Table 1 Chemical composition of AA 6061

\begin{tabular}{|l|l|l|l|l|l|l|l|l|l|}
\hline Element & $\mathbf{C r}$ & $\mathbf{C u}$ & $\mathbf{M g}$ & $\mathbf{F e}$ & $\mathbf{S i}$ & $\mathbf{M n}$ & $\mathbf{T i}$ & $\mathbf{Z n}$ & $\mathbf{A l}$ \\
\hline AA 6061 & 0.26 & 0.34 & 1.08 & 0.66 & 0.55 & 0.11 & 0.16 & 0.223 & balance \\
\hline
\end{tabular}

Die steel tool has a flat shoulder with $18 \mathrm{~mm}$ shoulder diameter along with a cylindrical pin of $2.5 \mathrm{~mm}$ length and $4 \mathrm{~mm}$ diameter. A bed of cast iron of dimension $320 \mathrm{~mm}$ lengths, $140 \mathrm{~mm}$ width and $20 \mathrm{~mm}$ height was made to clamp the workpiece during welding. The bed was prepared using a shaper machine. The thermocouple is used for measuring the value of temperature at a different point during the welding and the chemical composition of die steel is tabulated below in Table 2 . 
Table 2: Chemical composition of die steel

\begin{tabular}{|c|c|c|c|c|c|c|}
\hline Elements & $\begin{array}{c}\text { \% of } \\
\text { Carbon }\end{array}$ & $\begin{array}{c}\text { \% of } \\
\text { Silicon }\end{array}$ & $\begin{array}{c}\text { \% of } \\
\text { Manganes } \\
\text { e }\end{array}$ & $\begin{array}{c}\text { \% of } \\
\text { Chromiu } \\
\text { m }\end{array}$ & $\begin{array}{c}\text { \% of } \\
\text { Molybdenu } \\
\text { m }\end{array}$ & $\begin{array}{c}\text { \% of } \\
\text { Vanadiu } \\
\text { m }\end{array}$ \\
\hline Percentage & 1.50 & 0.30 & 0.40 & 12.00 & 1.00 & 0.90 \\
\hline
\end{tabular}

\section{Die steel tool}

The tool is used for welding the plate through the FSSW route. The tool plays a very important role nspot welding and heat transfer modeling. It was found from the literature survey that $80 \%$ of the heat generated due to friction by the shoulder of the tool and $10-20 \%$ heat generated due to pin profile. During the FSSW process as the welding was undergone at solidstate thus tool material should require a strong twisting moment and high melting point. One more property was required for analysis of heat transfer that the thermal conductivity of the tool should be minimum so that most of the heat generated should transfer from the plate only. Die steel material was selected for the tool making which was able to complete the requirements. The diameter of the shoulder is kept at $18 \mathrm{~mm}$. A tip is made which has a dimension of $\varnothing 4 \mathrm{~mm}$ and $2.5 \mathrm{~mm}$ in length. As shown in figure 2.

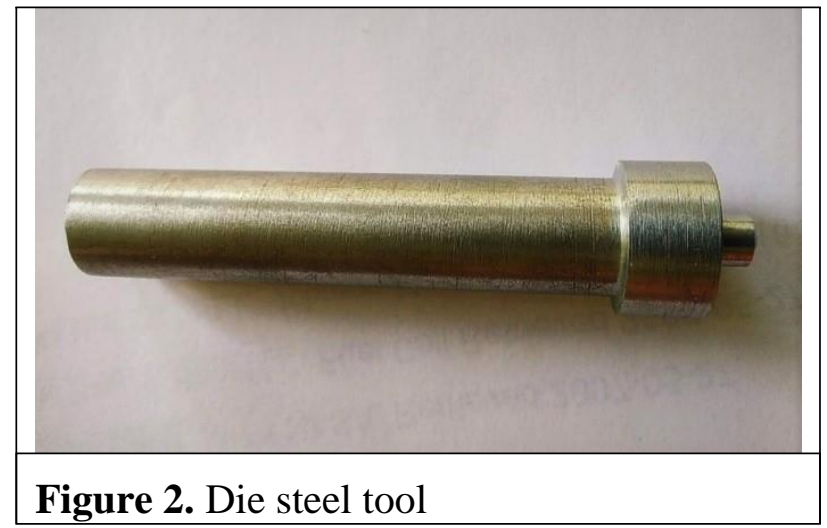

\section{Cast iron clamp}

During the welding of the plate, there was a requirement of fixing the plate; a cast iron plate was used to support the aluminium strip during friction stir spot welding. The cast iron plate can have 
a high damping capacity so that sound weld was as possible. Height of the bed of the radial drill machine was $320 \mathrm{~mm} \times 140 \mathrm{~mm} \times 20 \mathrm{~mm}$ as shown in figure 3 . The drill machine was configured as four stepped rotational speeds mentioned in Table 3. The spot-welded plate is shown in figure 4.

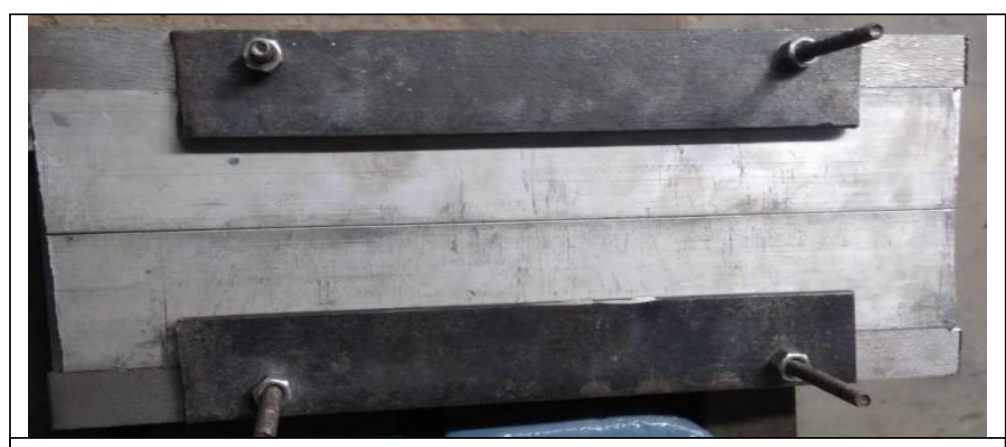

Figure 3. Clamping of Al strip on cast iron bed

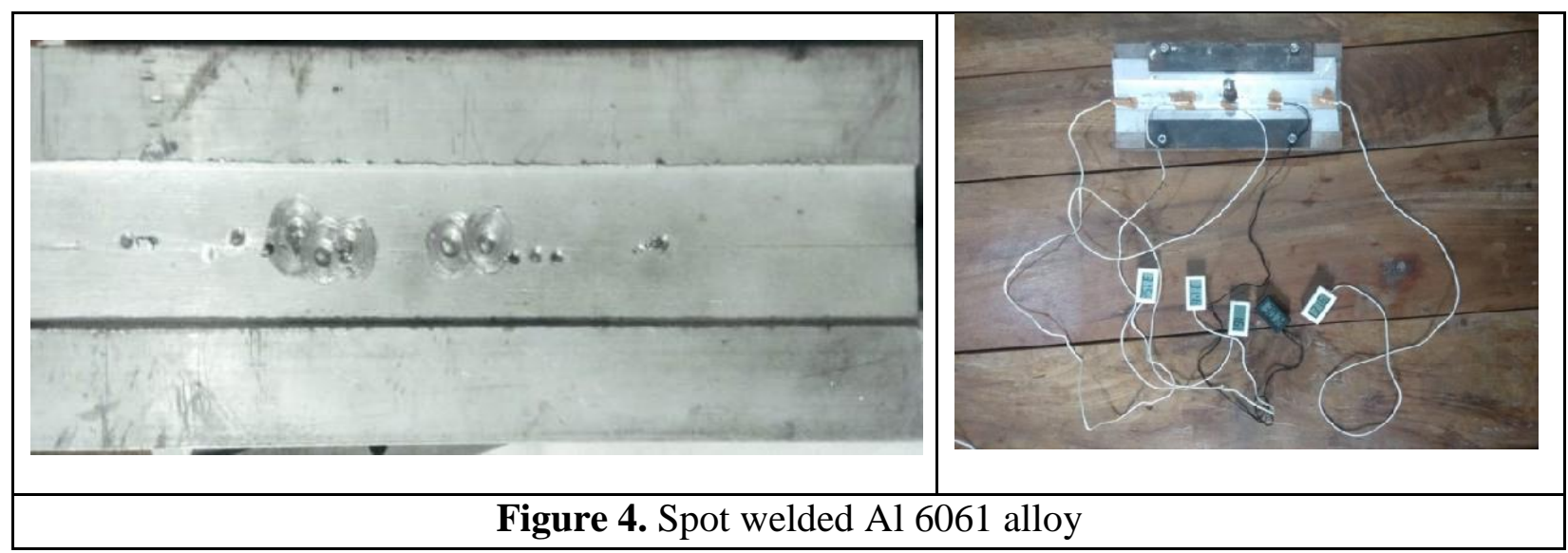

The heat transfer analysis was done with the help of recording temperature distribution along the spot weld. The line was made with a scriber which was at a $12 \mathrm{~mm}$ distance from the centerline. The thermocouple was placed at that position to monitor the temperature scale which is shown in table 3. During the friction stir spot welding (FSSW) of AA 6061 alloys, the tool was insertedinto the parent metal for welding purposes. 
Table 3: Fusion temperature of Al 6061 for different spindle speed

\begin{tabular}{|c|c|}
\hline $\begin{array}{c}\text { Spindle } \\
\text { Speed }\end{array}$ & $\begin{array}{c}\text { The Peak equilibrium temperature } \\
\text { atradius } \mathbf{+ 1 2} \mathbf{~ m m}(\text { in } \mathbf{C})\end{array}$ \\
\hline $1250 \mathrm{rpm}$ & 138 \\
\hline $1300 \mathrm{rpm}$ & 146 \\
\hline $1400 \mathrm{rpm}$ & 170 \\
\hline $1500 \mathrm{rpm}$ & 173 \\
\hline
\end{tabular}

The recorded temperature by the thermocouple based is mention below in Table 4

Table 4: Temperature history at $12 \mathrm{~mm}$ from the tool centre

\begin{tabular}{|c|c|c|c|c|}
\hline Time (sec) & $\begin{array}{c}\text { Temperature }\left({ }^{\circ} \mathbf{C}\right) \text { at } \\
\mathbf{1 4 0 0} \mathbf{~ r p m}\end{array}$ & $\begin{array}{c}\text { Temperature }\left({ }^{\mathbf{}} \mathbf{C}\right) \\
\text { at } \mathbf{1 2 5 0} \mathbf{~ r p m}\end{array}$ & $\begin{array}{c}\text { Temperature }\left({ }^{\circ} \mathbf{C}\right) \\
\text { at } \mathbf{1 3 0 0} \mathbf{~ r p m}\end{array}$ & $\begin{array}{c}\text { Temperature }\left({ }^{\circ} \mathbf{C}\right) \\
\text { at 1500 } \mathbf{~ r p m ~}\end{array}$ \\
\hline 0 & 30 & 30 & 30 & 30 \\
\hline 15 & 61 & 40 & 50 & 69 \\
\hline 30 & 98 & 52 & 69 & 101 \\
\hline 50 & 135 & 120 & 130 & 142 \\
\hline 70 & 163 & 130 & 140 & 170 \\
\hline 90 & 164 & 138 & 146 & 173 \\
\hline 110 & 141 & 120 & 135 & 155 \\
\hline 130 & 119 & 101 & 110 & 120 \\
\hline 150 & 95 & 80 & 85 & 102 \\
\hline 160 & 82 & 60 & 70 & 85 \\
\hline
\end{tabular}

The tool heats the base plate (AA 6061) due to frictional heat developed and it is heated below its melting point. Tool mixed the soft material of both the plate and pressure is applied to join this portion. So the total area deformed in the friction spot welding is an area where the tool was in contact with the base plate. The total deformed area calculated is found to be $10.20 \mathrm{~cm}^{2}$ shown in figure 5. 


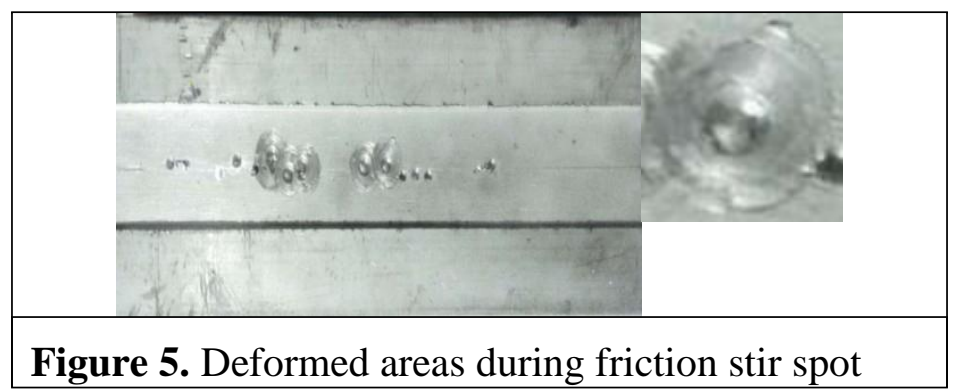

Modeling and Simulation

A coupled thermo-mechanical non-linear momentary based model was used on ANYSIS to simulate the friction stir spot welding (FSSW). To study the simulation a mesh-based model is created on Ansys. The workpiece is partitioned into two halves and one part is taken into consideration for the study. Since both parts are symmetric to one another to studying one part is sufficient to get the simulation result.

\section{Mathematical model}

For the mathematical model following assumptions are made.

The heat produced between the tool and the workpiece interface is due to friction betweenthem and this is called frictional heat.

The die steel tool is cylindrical and no thread is made on the tip of the tool.

If the local temperature reaches to melting point temperature of aluminium then no heat flows into it.

\section{Governing Equation}

During the friction stir spot welding process, the tool is rotating at constant speed at a fixed point on the joining line of two plates. A three-dimensional (3-D) heat transfer model is used to solve the problem of friction stir welding. This model is solved by using the energy conservation equation. This model involves the heat generated at the tool shoulder and flat plate interface of 
the workpiece and the rotating tool. The heat transfer equation can be expressed by equation (1). This equation is used in steady-state only.

$$
\frac{\partial}{\partial x_{i}}\left(-K \frac{\partial T}{\partial x_{i}}\right)+\rho C_{p} \mathrm{U} \frac{\partial T}{\partial x_{i}}=\mathrm{Q}-----(1)
$$

Where $i=1,2$ and 3 represents $\mathrm{x}, \mathrm{y}$ and $\mathrm{z}$-direction respectively. $\mathrm{K}=$ thermal conductivity of aluminium, $\rho=$ material density, $U=$ material flow velocity, $T=$ temperature of the material, $Q$ =heat input of welding, and $C_{p}=$ specific heat at constant pressure.

\section{Heat Generation}

The heat transfer of friction heat at the interface manly from the tool shoulder and pin. The shoulder and pin can conduct the heat to the base plate to be welded in solid-state condition only. During the rotation of the tool, the shoulder of the tool will always be in contact with the plate. Thus total heat transfer can be expressed as equation (2). This equation considers only conduction heat transfer because the heat was generated during friction only and the material was welded up to only $60 \%$ of the melting point.

$$
\begin{aligned}
& Q=Q_{\text {shoulder }}+Q_{\text {pin }------}(2) \\
& \text { Heat Input }
\end{aligned}
$$

\section{Heat Input}

It is assumed that heat generated at the interface was only due to friction. The study was not considered heat generation due to plastic deformation because severe plastic deformation was occurring due to the shape of tool and pin design. The heat input can be expressed as equation (3)

$$
Q_{f i}=2 \Pi \mu F_{n} R_{i} n------(3)
$$

speed of the tool and $F_{n}$ is the axial force applied by the tool on the workpiece. And $n$ was the rotational speed of the tool. The tool radius was $\mathrm{R}_{\mathrm{i}}$. The coefficient of friction between the tool and workpiece was not constant but it was considered as 0.3 for this mathematical modeling analysis. 


\section{Heat Input from the tool pin}

Heat transfer generation via tool pin consists of the three stages:

1) The heat generated during the shearing of the parent metal

2) The heat produced by the threaded present on the tool pin is due to friction.

3) The heat is generated via a vertical surface of the tool pin.

The heat produced by the tool pin is calculated by the relation given by the Colegrove.

Colegrove numerical relation is given as in equation (4).

$$
Q_{\text {pin }}=2 \pi r_{p} h \frac{Y(T)}{\sqrt{3}} V_{m}+\frac{2 \mu k Y r_{p} h V_{r p}}{\sqrt{3\left(1+\mu^{2}\right)}}+\frac{4 F_{p} \mu V_{m} \cos \varphi}{\pi}---(4)
$$

Here

$$
\begin{aligned}
& \Theta=90^{\circ}-\lambda-\tan ^{-1}(\mu) \\
& V_{r p} \\
& =\frac{\sin \theta}{\sin \left(180^{\circ}-\theta-\lambda\right)} v_{p} \\
& V_{m=\frac{\sin \lambda}{\sin (180-\theta-\lambda)} v_{p}} \\
& v_{p} \\
& =r_{p} w
\end{aligned}
$$

Here $\quad r_{p}$ is the radius of the tool pin, $\mathrm{Y}(\mathrm{T})$ is the average shear stress of the material and it is a function of temperature, $\mathrm{h}$ is the thickness of the workpiece, $\mathrm{F}_{\mathrm{p}}$ is the axial force during the welding, $\lambda$ is the helix angle of the thread, since the tip of the tool is cylindrical without thread so the value of helix angle is 0 or $90^{\circ}, \mu$ is the coefficient of friction between the workpiece and the tool. In this experimental work, the tool pin used was cylindrical shape without thread, hence only the primary term of Equation (4) is determined to find the heat input from the tool pin. 


\section{Result and discussion}

The FSSW was done on the aluminium plate of $5 \mathrm{~mm}$ thick, the half plate was considered for heat transfer analysis as shown in figure 6 . The double heat transfer will be the total heat transfer rate. The pin and shoulder both were considered for heat transfer elements. Then developed the geometry of the model was meshed for finite element analysis of heat transfer. There were two types of messing was done on the plate first uniform messing beyond the pin and stir zone and the second very fined messing at the stir zone. The fine messing yield good results. The messing is shown in figure 7 . The meshing was triangular.

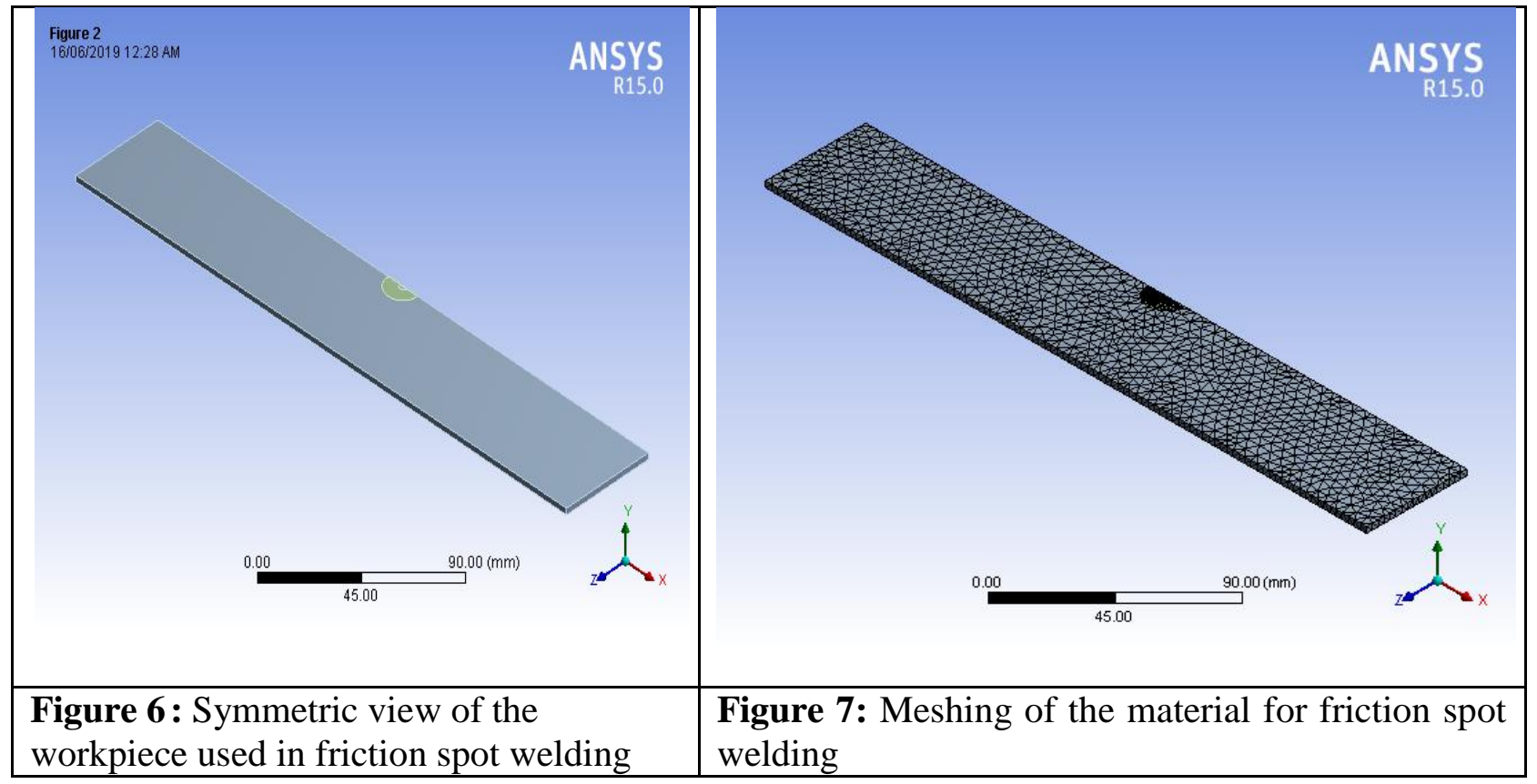

After messing was completed the model was analyzed for heat transfer analysis and it is found that the heat flow through the tool pin is approximately $1187 \mathrm{~W} / \mathrm{m}^{2}$. Heat flow through the tool shoulder is found to be $1257 \mathrm{~W} / \mathrm{m}^{2}$. In ANSYS 19.2, software heat flow is applied on the surface of the tooltip and tool shoulder. Total heat flow on friction welding is found to be $2444 \mathrm{~W} / \mathrm{m}^{2}$. The friction welding on the drilling machine and it is noted down that the full welding process is completed in 170 seconds. Welding time is taken as step size on ANSYS 19.2 software 
for the calculation. All the analysis is performed by taking step size as 170s. The heat flow through the pin is shown in figure 7 and heat flow through the shoulder is shown in figure 8.

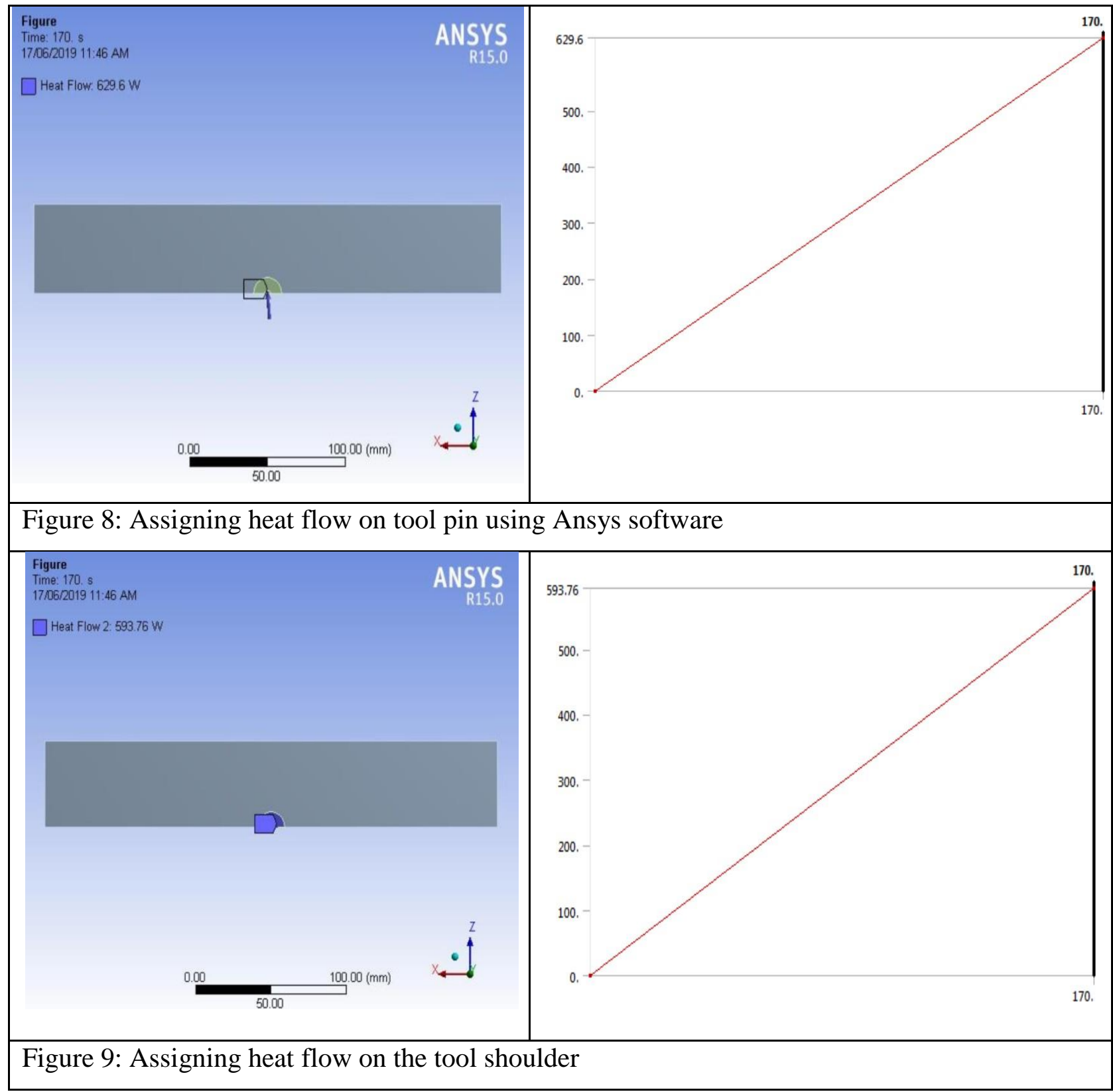

Three-Dimensional temperature distribution of friction spot welding of Al 6061 alloy Figure 6 shows the symmetric view of three-dimensional temperature distributions in theworkpiece during friction stir welding of AA 6061. As the heat source is applied at the centre, conductive heat transfer is considered in all directions within the workpiece. Convective heat transfer is also 
considered due to welding velocity increases. It is assumed that except for theconduction heat flow between the workpiece and tool some heat also flows on the workpiece dueto the convection. During analysis convection heat transfer is also assigned on the workpiece. The value of ambient air is taken as $27^{\circ}$ celsius. The air is assumed to be stagnant air and the value of the convection coefficient is taken as $5 \mathrm{~W} / \mathrm{m}^{2} \mathrm{C}$. Heat transfer takes place due to both conduction and convection, as can be seen in the isothermal contours showing asymmetric behavior. The peak temperature is approximately $60 \%$ of the melting point observed at the centre, and the temperature decreases away from the centre. It is clear from the thermal cycle that the peak temperature is generated is at the centre and it decreases towards the outerperiphery. As shown in figure 9.
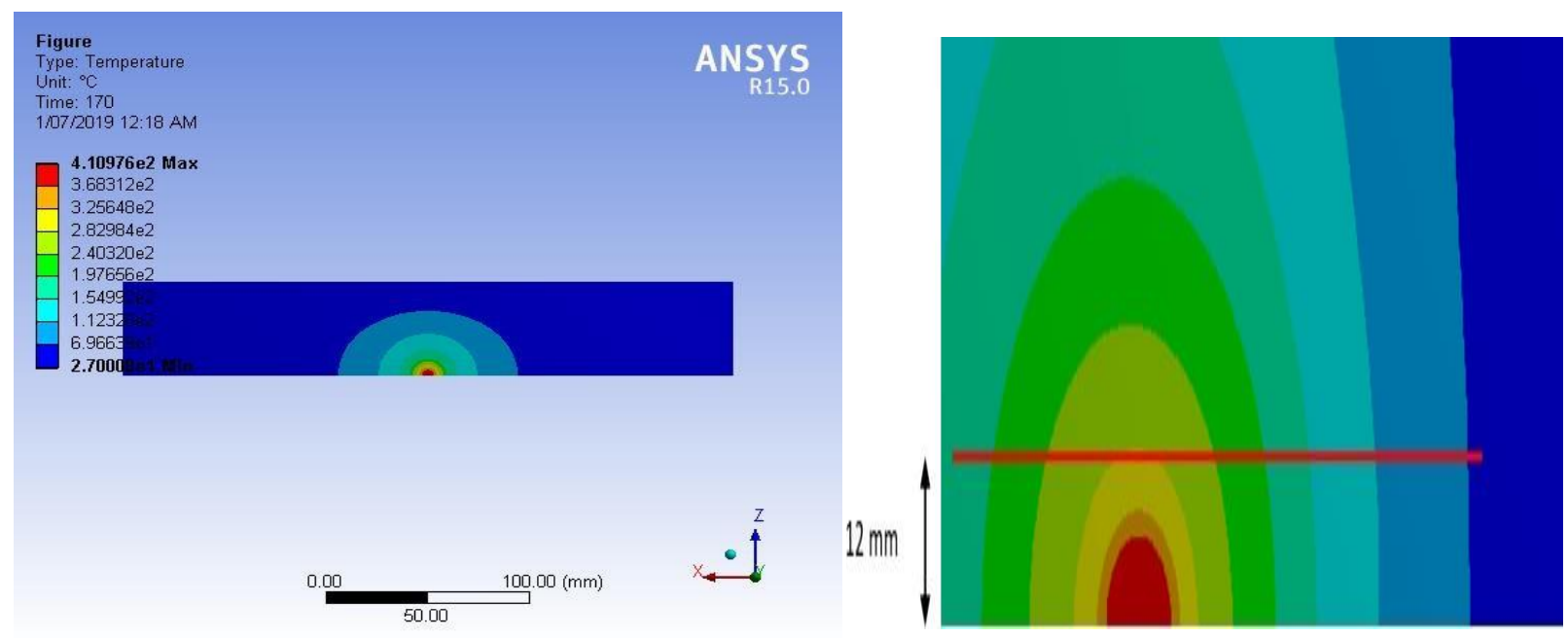

Figure 9 (a) Temperature distribution in the plate (b) Analysis of temperature at $12 \mathrm{~mm}$ from the centerline of welding

Variation of temperature with the distance of the plate of friction spot welding of Aluminum

From figure 10, it is clear that the temperature at the left and right end of the plate is ambient. As we move from the left end to the centre the temperature increases. While moving from the centre to the right end the temperature distribution decreases. A similar case was also observed in the case of $1300 \mathrm{rpm}$ rotational speed as shown in figure 10. 

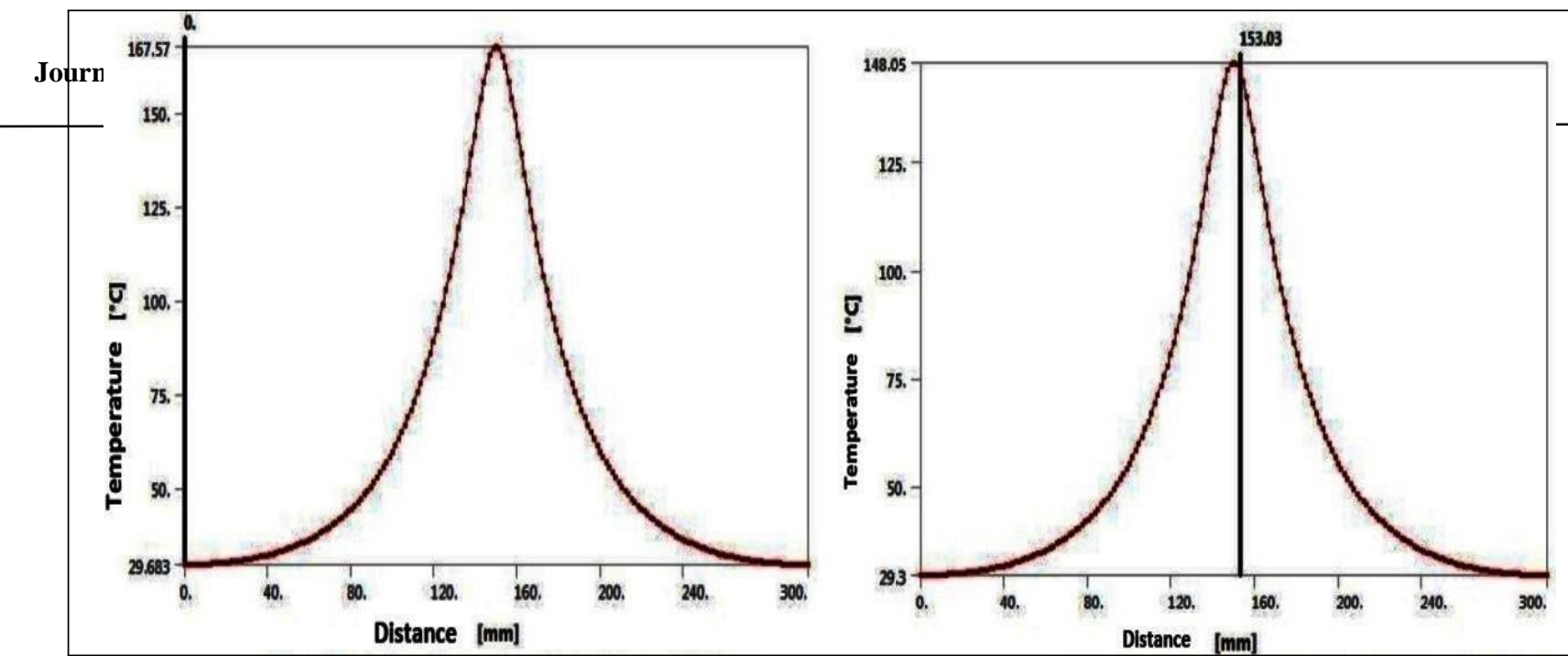

Figure 10 (a) variation of temperature with the Figure 10 (b) variation of temperature with the distance at $1500 \mathrm{rpm}$ distance at $1300 \mathrm{rpm}$

Comparisons of a numerical model with experimental data for friction stir spot welding of AA 6061

The experimental results and numerical results obtained from the Ansys modeling analysis were compared for the validation of the results. It was found that the temperature predicted by the experiments was not much diverted from the numerical values which are shown in figure 9 and 10 for $1300 \mathrm{rpm}$ and $1500 \mathrm{rpm}$.

\begin{tabular}{|l|l|l|l|l|}
\hline & \\
Figure 9. The variation between the computed \\
and measured temperature at $1300 \mathrm{rpm}$.
\end{tabular}

\section{Conclusion}

1. A 3-D heat transfer model was designed to predict the three-dimensional temperature distribution in friction stir spot welding (FSSW) of AA 6061.

2. The numerically computed temperature from the developed model has been compared with the experimentally measured values of temperatures at a particular position for a 
variety of tool rotational speeds.

3. The calculated and measured temperature is almost equal with $+2 \%$ to $-2 \%$ variations.

4. Maximum heat is generated at the centre and it decreases towards the outer periphery.

5. It is found from the experimental result that the temperature of fusion in the workpiece increases with increases in the spindle speed of the tool.

6. The temperature in the job increases with time and after the peak temperature is achieved temperature decreases with time.

7. The total destructive area is calculated to be $10.20 \mathrm{~cm}^{2}$.

\section{References}

Yang X., Li W., Li J., Xiao B., Ma T., Huang Z., Guo J.2015. Finite element modeling of the linear friction welding of GH4169 superalloy. Materials and Design 87, 215-230. doi: 10.1016 /j.matdes . 2015.08.036.

Singh R., Yadav A. 2018. Experimental studies of effect of process parameters for heat generation in friction stir welding. IOP Conference Series: Materials Science and Engineering, 402:1.doi: 10.1088/1757-899X/402/1/012131.

Jedrasiak P., Shercliff H R., McAndrew A R., Colegrove P A.2018. Thermal modelling of linear friction welding. Materials and Design 156, 362-369.doi: 10.1016/j.matdes.2018.06.043.

Leon J S., Jayakumar V. 2015. Investigation of Mechanical Properties of Aluminium 6061 Alloy Friction Stir Welding. International Journal of Students' Research in Technology \& Management 2(4): 140-144. doi: 10.5829/idosi.ije.2017.30.04a.19.

Singh R., Rizvi S A., Tewari S P. 2017. Effect of friction stir welding on the tensile properties of AA 6063 under different conditions. International Journal of Engineering Transactions A (Basics), 30(4): 597-603, doi: 10.5829/idosi.ije.2017.30.04a.19.

Gao Z., Niu J T., Krumphals F., Enzinger N., Mitsche S., Sommitsch C.2013. FE modelling of microstructure evolution during friction stir spot welding in AA6082-T6. Welding in the World. 
57(6):895-902.doi: 10.1007/s40194-013-0083-x.

Miyazaki Y., Tsumiyama K., Yamane T., Ito M., Shiozawa S. 2013. Kobe University Repository: Kernel. Kobe Journal of Medical Sciences. 59(2):64-71.

Zhu R., Gong, W B., Cui H. 2020. Temperature evolution, microstructure, and properties of friction stir welded ultra-thick 6082 aluminum alloy joints. International Journal of Advanced Manufacturing Technology, 108,331-343, https://doi.org/10.1007/s00170-020-05422-7.

Armansyah, Chie H H., Saedon J., Adenan S.2020. Temperature distribution in friction stir spot welding of aluminium alloy based on finite element analysis. IOP Conf. Ser. Earth Environ. Sci., 426:1.doi: 10.1088/1755-1315/426/1/012127.

Nguyen H P., Ngo N V., Nguyen Q T.2021. Optimizing process parameters in edm using low frequency vibration for material removal rate and surface roughness, Journal of King Saud University - Engineering Science, 33(4):284-291. doi: 10.1016/j.jksues.2020.05.002.

Ghetiya N D., Patel K M., Patel A B.2015. Prediction of temperature at weld line in air and immersed friction stir welding and its experimental validation. International Journal of Advanced Manufacturing Technology 79, 1239-1246. https://doi.org/10.1007/s00170-015-6906-8.

Peng C., Jing C., Siyi Q., Siqi Z., Shoubo S., Ting J., Zhiqing Z., Zhihong J., Qing L.2021. Friction stir welding joints of 2195-T8 Al-Li alloys: Correlation of temperature evolution, microstructure and mechanical properties. Materials Science and Engineering: A, 823, doi: 10.1016/j.msea.2021.141501. Ulysse P.2002. Three-dimensional modeling of the friction stir-welding process, International Journal of Machine Tools and Manufacture 42(14):1549-1557.doi: 10.1016/S0890-6955(02)00114- 1.

Bilgin M B., Gok K., Gok A.2017. Three-dimensional finite element model of friction drilling process in hot forming processes. Proceedings of the Institution of Mechanical Engineers, Part E: Journal of Process Mechanical Engineering, 231(3):548-554. 